\title{
THE BIPHASIC NATURE OF PILOT ERROR IN GLIDING ACCIDENTS
}

\author{
B. JAMES, M.B., B.S.
}

Cherry Orchard, Marlow Common, Buckinghamshire

Although the proportions may vary in different sports, sportsmen indulge in mental activity as well as muscular activity; sometimes under conditions of considerable stress or arousal.

The relationship between the performance of a learning task and the level of arousal was first described by Yerkes and Dodson in 1906 and was based on experiments in which white mice were subjected to electric shocks. Their findings were described as the Yerkes-Dodson Law which states that there is an optimum level of arousal for the performance of a skilled task and that this optimum value falls as the difficulty of the task is increased. This law has been widely confirmed in a large number of experimental situations. Applying it to sporting activity we can use chess and rowing as examples.

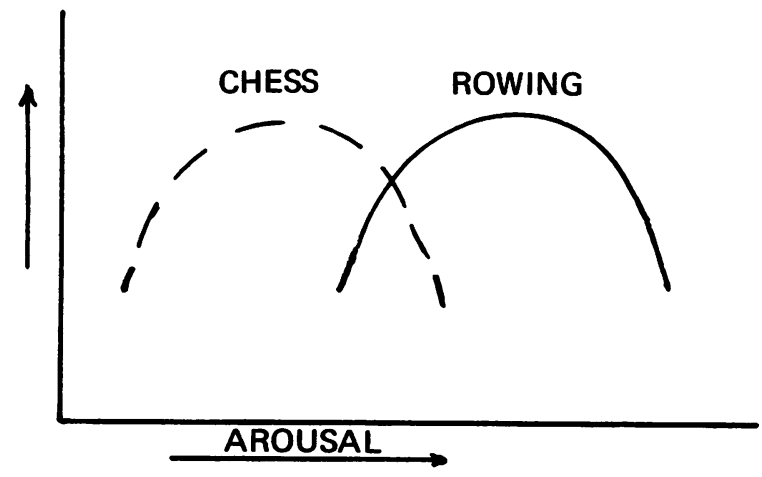

Fig. 1 Performance

In chess the mental activity is difficult and the optimum level of arousal is low, when players are allowed to play in peace. In rowing the emphasis is mainly on muscular activity and here it is felt that cheering and applause leads to an improvement in performance.

The consumption of drugs of the amphetamine group has the effect of increasing the level of arousal so it is clearly apparent that it will have a more advantageous effect on the oarsman than the chess grandmaster, this in fact might be a profitable field for experimentation. When we come to consider the mental activities of a glider pilot we can regard him as progressing along the branches of a logical tree, being constantly faced with the need to decide which branch to take (fig 2). 


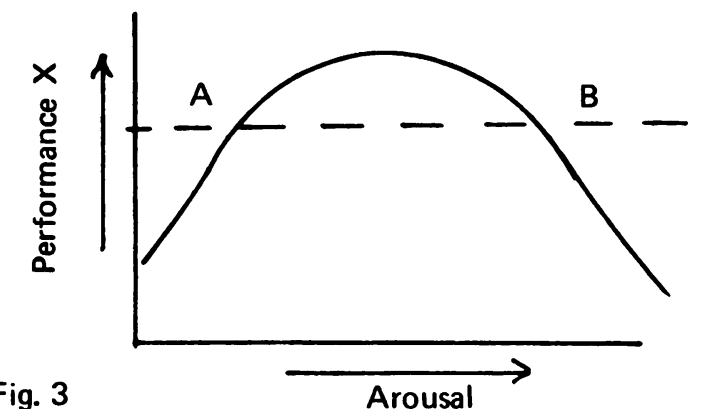

Fig. 3

Arousal

those due to mistakes on the part of the pilot it appears that they can be divided into two roughly equal groups corresponding to states of low or high arousal.

It need not be emphasized that since the interpretation of the accident history requires an assessment of the pilot's mental state at the time of the accident a considerable subjective element is involved, however in many cases there is little doubt on the matter. In general there is a considerable difference in the character of the case history in the two categories. In the low arousal state accident the history is often short and simple. 'Pilot fails to lower his undercarriage on landing' is a good example.

In the high arousal state accident the story is often relatively lengthy and complicated. The Launch Cable breaks when the glider is about $\mathbf{3 0 0}$ feet high, the pilot attempts to fly a circuit with inadequate height and spins into the ground on his final turn. Here the emergency of a cable break which is the precipitating factor, puts the pilot into a high arousal state and although the initial emergency is adequately dealt with, the reduction in skill causes an accident not directly connected with the original emergency.

From the practical point of view we are in effect considering two quite separate complaints and the means of prevention may well differ. It is reasonable in fact to suspect that when the level of flying discipline is unnecessarily high a reduction in low arousal state accident may be bought by a rise in high arousal state accidents.

Another effect may be observed in practice. If the effect of the mistake is not immediately catastrophic the pilot will be startled and his arousal state will rise. If he was previously in a low arousal state the effect will be to increase his skill and prevent another mistake, in other words the system has negative feedback. If he was already in a high arousal state the effect will be to reduce his skill and make another mistake more likely, a positive feedback situation.

This explains why the high arousal state accident often has a complicated case history. Extrapolating to other sports such as golf it is apparent that the player must not only have considerable skill, he must control his level of arousal to maintain his position on the crest of his performance curve. Once he begins to drift to the right of the curve his performance will continue to deteriorate. It is a well known phenomenon how a golfer can go to pieces after a bad score at one hole. Since giving this address to the World Congress the author has been informed that footballers are often warned that the times when their opponents are most likely to score against them are after they have scored themselves (low arousal state) or immediately after they have been scored against (high arousal state). (or should these last interpretations be reversed?)

Preventive measures which may be considered are the education of sportsmen to the fact that their skills may fail them at levels of high or low arousal and that measures of emotional self control are required. Secondly by the repeated exposure to stress e.g. by public competition the sportsman may build up a tolerance for high arousal states. Finally when the activity involves considerable danger it must be planned to constitute a fail safe situation so that few mistakes can be cumulative or catastrophic.

\section{REFERENCES}

1. HEBB, D. O. 1955 Drives and the CNS. Psychol. Review 62, 234-54

2. MALMO, R. B. 1959 Activation in a neuro psychological dimension control. Psychol. Review 66, 367-86

3. FREEMAN, G. L. 1940 The relation between performance level and bodily activity level J. Exp. Psychol 26, 602-8

4. CORCORAN, D. W. J. 1965 Brit. J. Psychol 56, 203, 267-273

5. JAMES, D. B. 1963 The Nature of Accidents, Sailplane and gliding 454-456

6. ibid 1969 The Biphasic Nature of Pilot Error in gliding accidents. Flight Safety 3, No. 3 